\title{
Application of Selective Bronchial Intubation versus Neurally Adjusted Ventilatory Assist in the Management of Unilateral Pulmonary Interstitial Emphysema: An Illustrative Case and the Literature Review
}

\author{
Shing-yan Robert Lee, MRCP (UK), FHKAM ${ }^{1}$ \\ ${ }^{1}$ Department of Paediatrics and Adolescent Medicine, Pamela Youde \\ Nethersole Eastern Hospital, Chai Wan, Hong Kong \\ Am J Perinatol Rep 2017;7:e101-e105.
}

\begin{abstract}
Address for correspondence Shing-yan Robert Lee, MRCP (UK), FHKAM, Department of Paediatrics and Adolescent Medicine, Pamela Youde Nethersole Eastern Hospital, 3 Lok Man Road, Chai Wan, Hong Kong (e-mail: leesyr@netvigator.com).
\end{abstract}

\author{
Abstract \\ Keywords \\ - unilateral pulmonary \\ interstitial \\ emphysema \\ - prematurity \\ - neonate \\ - selective bronchial \\ intubation \\ - neurally adjusted \\ ventilatory assist \\ - NAVA
}

In the treatment of left-sided pulmonary interstitial emphysema (PIE) in a 23-week neonate, we used two ventilatory strategies: selective bronchial intubation from day 10 to 15 and neurally adjusted ventilatory assist (NAVA) from day 18 to 26. We compared the effects and adverse effects of these two strategies. On selective bronchial intubation, desaturation was frequent. Fentanyl infusion was required. There was an episode of carbon dioxide retention coupled with hypotension. On NAVA, the neonate was clinically stable without the requirement of sedation. On selective bronchial intubation, ventilator setting in terms of mean airway pressure and oxygen requirement was higher, which came down on the first day of NAVA. Radiologically unilateral PIE did not resolve and became localized in the left middle zone of lung field on selective bronchial intubation. Also, the lobar collapse of ipsilateral, as well as contralateral lungs occurred. On NAVA, unilateral PIE resolved. NAVA might be a good option for the management of unilateral PIE.
Selective bronchial intubation was impressively successful in the management of 46 neonates with a unilateral air leak, and it was associated with only mild and reversible complications according to a review by Joseph et al. ${ }^{1}$ Recently, it was reported that neurally adjusted ventilatory assist (NAVA) mode of ventilation available in SERVO-i ventilator (Maquet, Solna, Sweden) resulted in resolution of localized pulmonary interstitial emphysema (PIE) in two neonates. ${ }^{2}$ To date, there has been no comparison between the two strategies in the management of unilateral PIE: selective bronchial intubation versus NAVA. We report a case of a premature neonate with unilateral PIE treated initially by selective bronchial intubation. Subsequently, intubation was switched to endotracheal intubation with the tip of endotracheal tube withdrawn above the carina. NAVA mode of ventilation was commenced. Our case provides an opportunity to gain an understanding of the pros and cons of these two management strategies.

\section{Case Report}

A 23-week-old male neonate with birth weight $865 \mathrm{~g}$ was treated by two doses of surfactant at 1 and 12 hours of life. After surfactant therapy, ventilator setting was weaned down to peak inspiratory pressure (PIP) of $13 \mathrm{cmH}_{2} \mathrm{O}$ and $\mathrm{FIO}_{2} 21 \%$ on conventional intermittent positive pressure ventilation. He developed pulmonary hemorrhage at 35 hours of life. Left-sided PIE then developed (-Fig. 1). At 41 hours of life, ventilation was changed from conventional received

October 26, 2016 accepted after revision March 27, 2017
DOI https://doi.org/

10.1055/s-0037-1603322. ISSN 2157-6998.
Copyright $\odot 2017$ by Thieme Medical Publishers, Inc., 333 Seventh Avenue, New York, NY 10001, USA. Tel: +1(212) 584-4662.
License terms

(요 (1) $\Theta$ 


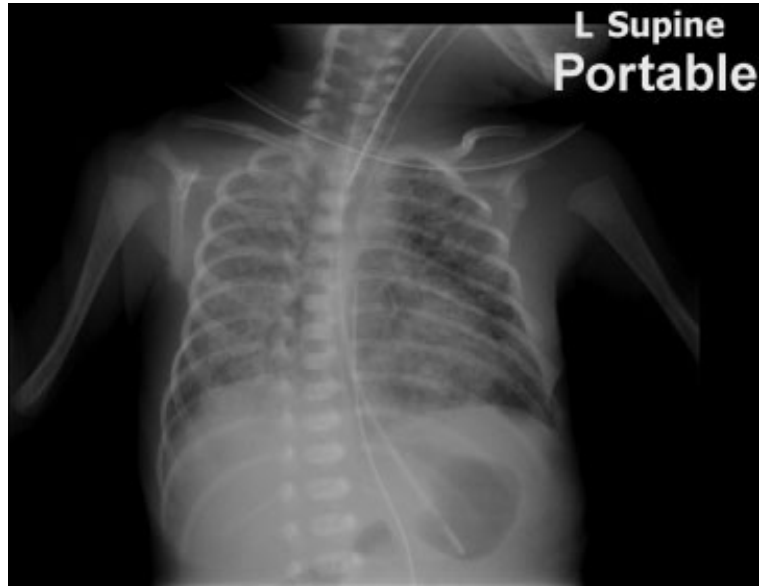

Fig. 1 Early signs of left-sided pulmonary interstitial emphysema at 41 hours of life occurring after pulmonary hemorrhage.

ventilation to high-frequency oscillatory ventilation (HFO) (Sensormedics 3100A, Yorba Linda, CA) in the hope of delivering less barotrauma. Mean airway pressure (MAP) of $7.5 \mathrm{cmH}_{2} \mathrm{O}$ and $\mathrm{FIO}_{2}$ of $50 \%$ were used, in keeping with the low volume strategy of HFO. The amplitude was 20 $\mathrm{cmH}_{2} \mathrm{O}$ and rate was $15 \mathrm{~Hz}$. We also put the patient to lie laterally on the left side. Despite all these efforts, PIE, as revealed by the chest X-ray, worsened (-Fig. 2). The strategy of selective bronchial intubation was applied on day 10 . The endotracheal tube was advanced into the right main bronchus. This was done in the hope that the left lung could be spared of ventilation and could recover from PIE. After intubation of the right lung, HFO setting needs to be increased to $\mathrm{FiO}_{2} 50 \%$, MAP of $8.5 \mathrm{cmH}_{2} \mathrm{O}$, and amplitude to 24 $\mathrm{cmH}_{2} \mathrm{O}$. On day 12, there was frequent desaturation, and at times oscillatory vibration was not observed on his chest. Therefore, we stopped HFO and put the patient back to

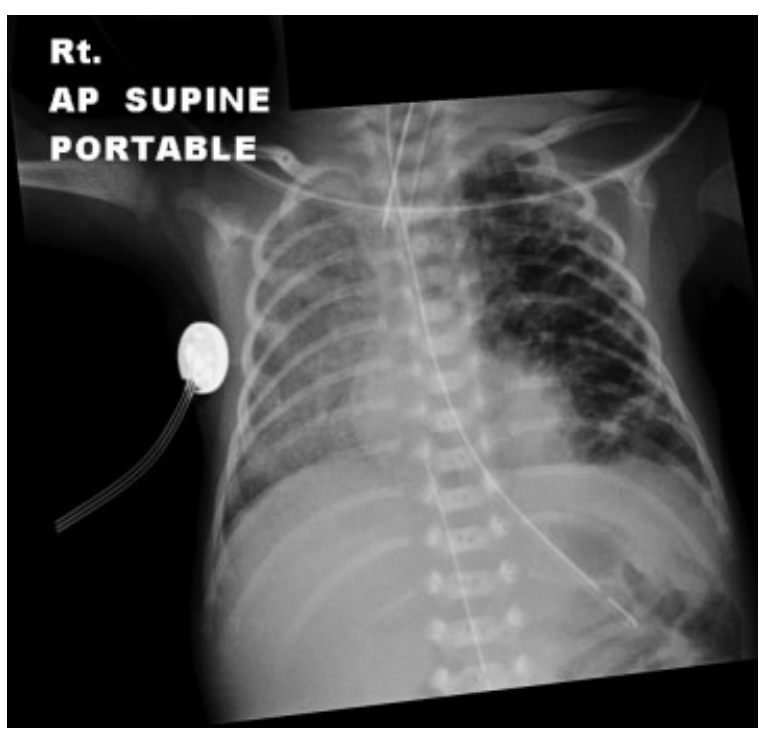

Fig. 2 Pulmonary interstitial emphysema worsened on day 10 when selective bronchial intubation was started.

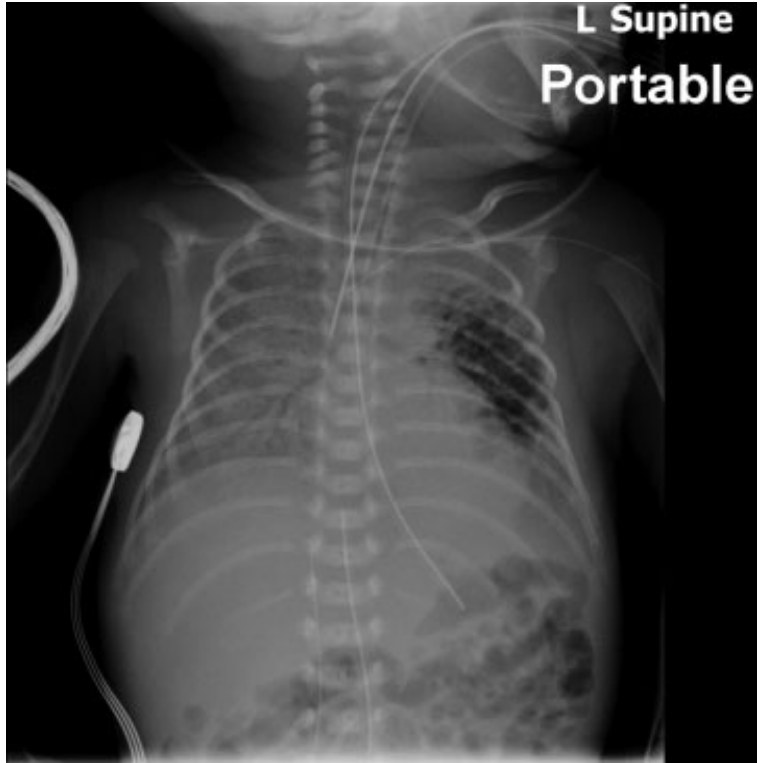

Fig. 3 Persistent pulmonary interstitial emphysema change in left middle lung field with atelectasis of rest of the lungs on day 14 when selective bronchial intubation was already undertaken for 4 days.

conventional intermittent positive pressure ventilation using PIP $16 \mathrm{cmH}_{2} \mathrm{O}$, positive end-expiratory pressure (PEEP) $5 \mathrm{cmH}_{2} \mathrm{O}$, inspiratory time 0.4 seconds, and $\mathrm{FIO}_{2} 30 \%$ while pursuing selective bronchial intubation. We used "SIMV with pressure support" mode on an SERVO-i ventilator. What happened to the chest X-ray during selective bronchial intubation was that PIE change became localized in the middle zone of the left lung with areas of atelectasis in the rest of the lungs (-Fig. 3). During selective ventilation, there was frequent desaturation requiring ambu bagging. On day 15 there was an episode of desaturation, carbon dioxide retention, and hypotension. Selective bronchial intubation was thus aborted. We commenced bilateral lung ventilation with HFO. From day 15 to $19, \mathrm{FiO}_{2}$ crept up from 50 to $90 \%$. MAP was increased from 9 to $11 \mathrm{cmH}_{2} \mathrm{O}$. On day 18 , ventilator mode was changed to NAVA. Before changing to NAVA, the patient was sedated with fentanyl infusion. In preparation for NAVA, which relied on the diaphragmatic signal, we took off fentanyl infusion and loaded the patient with caffeine citrate. The initial NAVA setting was $\mathrm{FIO}_{2} 35 \%$, PEEP $5 \mathrm{cmH}_{2} \mathrm{O}$, and NAVA level of 3. Apnea time was set at 5 seconds, which by design recruited backup pressure control when there was no diaphragmatic signal detected for 5 seconds. Edi peak was variable ranging from 7 to 12 with average 9 and Edi min ranging from 2 to 5 with average 3 in the first day of NAVA. The patient was more stable on NAVA regarding oxygen saturation. Over the days $\mathrm{FiO}_{2}$ decreased from $100 \%$ to $25 \%$. MAP decreased from $12 \mathrm{cmH}_{2} \mathrm{O}$ to $8 \mathrm{cmH}_{2} \mathrm{O}$. NAVA level was weaned to 2 . Edi peak was down to an average of 4 and Edi min was down to an average of 1 before extubation. PIE change gradually improved as revealed by chest X-ray. On day 25 there was complete resolution of PIE change in the chest X-ray (-Fig. 4). Therefore, the patient was successfully extubated on day 26 . 


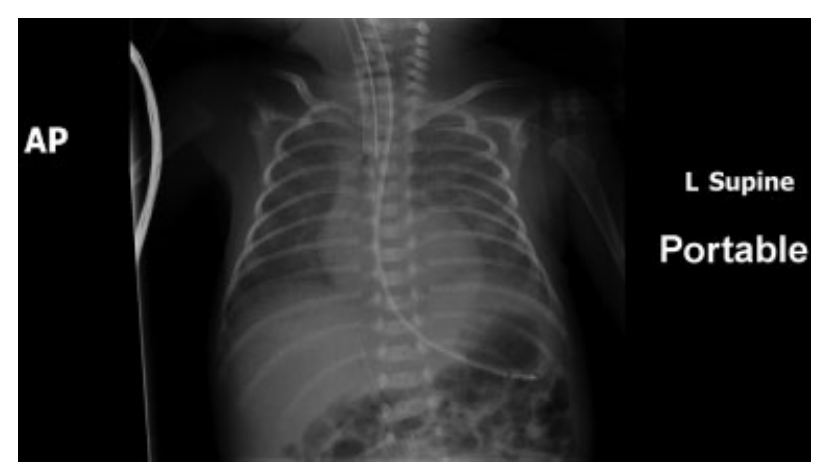

Fig. 4 Resolution of pulmonary interstitial emphysema 7 days after neurally adjusted ventilatory assist was commenced.

\section{Discussion}

A review by Joseph et $\mathrm{al}^{1}$ showed that selective bronchial intubation was successful in resolving unilateral air leak in 46 neonates with few mild complications. After this large review, there were further publications about the success of selective bronchial intubation in two premature neonates with a unilateral air leak. ${ }^{3,4}$ Contrary to these cases, our case showed that selective bronchial intubation failed to resolve PIE and there were severe complications during selective bronchial intubation. Why was our case different?

First, the biggest review showing the success of selective bronchial intubation in the management of 46 neonatal cases of unilateral air leak had selection bias. ${ }^{1}$ This review collected case reports or case series published in English literature spanning the period from 1977 to $2010 .{ }^{1}$ However, this review ${ }^{1}$ did not include unsuccessful cases reported in the literature and thus was a review presenting a biased view toward the safety and efficacy of selective bronchial intubation. For example, they only included nine successful cases from the case series of Glenski et al in their review but dropped the four unsuccessful cases from the same case series of Glenski et al. ${ }^{5}$ This review did not include a case series about three premature neonates treated by selective bronchial intubation either ${ }^{6}$ as none of these neonates had improvement. Lately, there was a recent publication about nine neonates treated by selective bronchial intubation for a unilateral air leak, in which two cases were unsuccessful. ${ }^{7}$ These three case series serve to illustrate that indeed selective bronchial intubation could be unsuccessful at times. ${ }^{5-7}$ Therefore, it was not surprising that we encountered yet another case of failure of selective bronchial intubation.

Furthermore, we feel obliged to highlight the possibility of serious complications during selective bronchial intubation, and we strongly issue a word of caution when selective bronchial intubation is contemplated. Our patient was quite unstable during the period of selective bronchial intubation having recurrent desaturation, carbon dioxide retention, and hypotension. In fact, the common occurrence of serious complications was reported by Glenski et al. ${ }^{5}$ Glenski et al reported that 15 of 32 cases in the literature and their case series had serious complications. ${ }^{5}$ Desaturation and hypoxia were common. ${ }^{1,5}$ Collapse/atelectasis frequently oc- curred. ${ }^{1,5}$ Atelectasis could have serious consequence and could lead to fatal outcome. A 29-week-old neonate after the commencement of selective bronchial intubation developed right upper lobe collapse and had severe hypoxia. ${ }^{5}$ Severe intraventricular hemorrhage followed this, and the neonate died 24 hours later. Another 29-week-old neonate developed pneumonia in the lung made atelectatic by selective bronchial intubation and died secondary to pulmonary insufficiency. ${ }^{5}$ On the contrary, neonates were more stable and were free of complications according to our current case report, and the previous case report of NAVA use. ${ }^{2}$

Reviewing the chest X-ray in detail for our patient when right lung was selectively intubated ( - Fig. 3) might throw light to why this strategy might not work. The end of the endotracheal tube was advanced beyond the carina. However, the bevel of the endotracheal tube was wedge shaped and could have provided some ventilation to the contralateral lung when the bevel faced the carina. We also believed that any slight shifting of the position of the endotracheal tube could have contributed to episodes of bradycardia, carbon dioxide retention and loss of vibration while on HFO in our case. In theory, the best position of the end of the endotracheal tube should just pass the carina but is open to ventilate the three lobar bronchi. In practice, the right upper lobar bronchus, which is the most proximal lobar bronchus, is often occluded by endotracheal tube during selective bronchial intubation. Further advancement of the endotracheal tube results in ventilation of the right lower lobe only with occlusion of the right middle lobar bronchus. Occlusion of these lobar bronchi might result in loss of ventilation of the corresponding lobes and lobar collapse. In reality, the slight shifting of the endotracheal tube is not often preventable as current methods for fixing endotracheal tube like using NeoBars (Neotech) or taping are not 100\% steadfast with room for shifting. This underscores the difficulty in applying selective unilateral ventilation for micropremies.

The other problem reported in the literature concerning the use of selective bronchial intubation is a recurrence of PIE. Following resolution of unilateral PIE, selective bronchial intubation is converted to endotracheal intubation. Then unilateral PIE might recur, and this has been described before. ${ }^{7-9}$ In contrast, unilateral PIE did not recur with the use of NAVA in our case and the previous case report of NAVA use. $^{2}$

We find from the literature that selective bronchial intubation might yield more drastic improvement when overdistended lung with air leak herniated and compressed on the contralateral lung causing respiratory embarrassment. It was because under these circumstances selective bronchial intubation might provide rapid decompression of the overinflated lung. In fact, some of the success cases of selective bronchial intubation happened when unilateral air leak was said to be life-threatening, ${ }^{10}$ caused rapid deterioration ${ }^{8}$ or resulted in the requirement of high ventilator settings. ${ }^{11}$ In our case, despite the development of unilateral PIE, the patient was easily ventilated with low ventilator setting at first. Therefore, there could not be any "drastic" clinical improvement to see. In the previous report of two patients 
Table 1 Comparison of two ventilatory strategies

\begin{tabular}{|c|c|c|}
\hline & Selective bronchial intubation & NAVA \\
\hline Chance of success in resolution & May not always be successful & $\begin{array}{l}\text { Successful in all the } 3 \text { cases so far } \\
\text { reported }\end{array}$ \\
\hline Requirement for sedation & Yes & No \\
\hline $\begin{array}{l}\text { Intricacy of placement of endotra- } \\
\text { cheal tube }\end{array}$ & $\begin{array}{l}\text { Change of direction of bevel of en- } \\
\text { dotracheal tube might undermine } \\
\text { the desired effects; Slight shifting } \\
\text { of endotracheal tube could occlude } \\
\text { upper and middle lobar bronchi }\end{array}$ & $\begin{array}{l}\text { Easy placement of endotracheal } \\
\text { tube }\end{array}$ \\
\hline $\begin{array}{l}\text { Complications } \\
\text { Collapse/atelectasis } \\
\text { Desaturation }\end{array}$ & $\begin{array}{l}\text { Common } \\
\text { Could be frequent in some patients }\end{array}$ & $\begin{array}{l}\text { Probably rare } \\
\text { Infrequent }\end{array}$ \\
\hline $\begin{array}{l}\text { Recurrence of unilateral PIE after } \\
\text { cessation of treatment }\end{array}$ & Possible in some cases & Probably unlikely \\
\hline $\begin{array}{l}\text { Indication proposed (and expected } \\
\text { course) }\end{array}$ & $\begin{array}{l}\text { May have a role in case of life- } \\
\text { threatening over-distension of ipsi- } \\
\text { lateral lung compressing contralat- } \\
\text { eral lung (drastic improvement } \\
\text { might ensue) }\end{array}$ & $\begin{array}{l}\text { For most other cases of PIE NAVA } \\
\text { provides a gentler approach (NAVA } \\
\text { usually resolves PIE gradually within } \\
10 \mathrm{~d} \text { ) }\end{array}$ \\
\hline
\end{tabular}

Abbreviations: NAVA, neurally adjusted ventilator assist; PIE, pulmonary interstitial emphysema.

managed with $\mathrm{NAVA}^{2}$ and in our case, we observed that improvement on NAVA was gradual and it took eight to ten days for the unilateral PIE to resolve completely.

There was a report of 10 neonates with congenital diaphragmatic hernia $(\mathrm{CDH})$ crossed over from pressure support ventilation (PSV) to NAVA after a hernia was surgically repaired. ${ }^{12}$ NAVA showed superiority over PSV in terms of improved oxygen-linked index, lower $\mathrm{pCO}_{2}$ and lower peak inspiratory pressure. In these cases of $\mathrm{CDH}$, the lungs on two sides had different compliance: a relatively normal lung on one side and a hypoplastic lung on the other side. These cases were similar to our case of unilateral PIE with the presence of lungs of different compliance on two sides. The author ${ }^{12}$ came up with the following postulation for the usefulness of NAVA in the ventilation of two lungs with different compliance. The optimization of ventilatory support is a crucial issue in the management of $\mathrm{CDH}$, in which the objective of weaning and the return to spontaneous breathing should be pursued trying to balance the two lungs and using ventilatory strategies to prevent pulmonary damage in the hypoplasic lung, without over-inflating the non-CDH lung. This discrepancy can be overcome with more difficulty during PSV, which could lead to excessive volume delivery and over-distention since expiration is not neurally detected, whereas during NAVA cycling-off occurs when the diaphragm activity is turned off by the respiratory centers and hence should provide a more physiologic termination of assist.

Also, the success in the resolution of unilateral PIE on NAVA could be understood given the built-in design of NAVA. Neurally generated diaphragmatic signal generates each ventilator breath. This ventilator breath is terminated once the appropriate tidal volume is reached due to the HerringBreuer reflex. This way the most appropriate tidal volume and thus PIP is delivered disallowing the production of excessive volume and excessive pressure obviating volutrauma and barotrauma. With the elimination of volutrauma and barotrauma, PIE gradually improves. This theory has support from that switch-over studies ${ }^{13-15}$ in which conventional ventilation is switched to NAVA. PIP measured becomes smaller after switch over. ${ }^{13-15}$ Our case is the third case of successful resolution of unilateral PIE on NAVA ventilation reported in the literature. In the previous report of the two neonates with localized PIE resolving on NAVA, ${ }^{2}$ PIP measured did diminish once NAVA mode was commenced. In our case, we observed MAP was described on switching ventilation from HFO to NAVA.

Based on our case and review of the literature, we draw up a table comparing the use of selective bronchial intubation and NAVA in the management of unilateral PIE ( - Table $\mathbf{1}$ ). In conclusion, we caution that selective bronchial intubation is not without risk and serious complications could occur. NAVA might provide a gentler option of ventilation achieving resolution of unilateral PIE.

Conflict of Interest

None.

\section{References}

1 Joseph LJ, Bromiker R, Toker O, Schimmel MS, Goldberg S, Picard E. Unilateral lung intubation for pulmonary air leak syndrome in neonates: a case series and a review of the literature. Am J Perinatol 2011;28(02):151-156

2 Lee SR, Shek CC. Resolution of localized pulmonary interstitial emphysema in two neonates - Why does neurally adjusted ventilatory assist work? J Clin Neonatol 2015;4(02):115-118

3 Corsini I, Pratesi S, Dani C. Pulmonary interstitial emphysema after resolution of relapsing pneumothorax and discontinuation 
of mechanical ventilation. An atypical case in a preterm infant. J Matern Fetal Neonatal Med 2014;27(15):1610-1612

4 Balegar VKK, Barr PA, McCauley JC, Thomas G. Selective bronchial intubation in a preterm infant with congenital cystic adenomatoid malformation and pulmonary air leak syndrome. J Paediatr Child Health 2013;49(01):e93-e96

5 Glenski JA, Thibeault DW, Hall FK, Hall RT, Germann DR. Selective bronchial intubation in infants with lobar emphysema: indications, complications, and long-term outcome. Am J Perinatol 1986;3(03):199-204

6 Milner AD, Field D, Hopkin IE, Tyrell J. Selective bronchial intubation for pulmonary emphysema. Arch Dis Child 1985;60(01):83-84

7 Jakob A, Bender C, Henschen M, et al. Selective unilateral lung ventilation in preterm infants with acquired bullous emphysema: a series of nine cases. Pediatr Pulmonol 2013;48(01):14-19

8 Oliver JE, Smith IJ. Treatment of severe localized pulmonary interstitial emphysema by selective bronchial intubation. Postgrad Med J 1984;60(699):58-59

9 Campbell AN, Zarfin Y, Perlman M. Selective bronchial intubation for pulmonary emphysema. Arch Dis Child 1984;59(09):890-892
10 Holzki J, Kellner M. Life threatening unilateral pulmonary overinflation might be more successfully treated by contralateral selective intubation than by emergency pneumonectomy. Paediatr Anaesth 2003;13(05):432-437

11 Placzek MM, Young LW. Unilateral pulmonary interstitial emphysema and selective bronchial intubation. Am J Dis Child 1986; 140(02):161-162

12 Gentili A, Masciopinto F, Mondardini MC, Ansaloni S, Reggiani ML, Baroncini S. Neurally adjusted ventilatory assist in weaning of neonates affected by congenital diaphragmatic hernia. J Matern Fetal Neonatal Med 2013;26(06):598-602

13 Bengtsson JA, Edberg KE. Neurally adjusted ventilatory assist in children: an observational study. Pediatr Crit Care Med 2010; 11(02):253-257

14 Stein H, Howard D. Neurally adjusted ventilatory assist in neonates weighing $<1500$ grams: a retrospective analysis. J Pediatr 2012;160(05):786-9.e1

15 Lee J, Kim HS, Sohn JA, et al. Randomized crossover study of neurally adjusted ventilatory assist in preterm infants. J Pediatr 2012;161(05):808-813 